\title{
Ponderações sobre a relevância dos espaços verdes urbanos para as condições de saúde e qualidade de vida
}

\author{
Considerations on the relevance of urban green spaces for the health and quality of life
}

Consideraciones sobre la relevancia de los espacios verdes urbanos para la salud y la calidad de vida

Lidiane Aparecida Alves

Professora Doutora Substituta, UFU, Brasil. lidianeaa@yahoo.com.br 

população. De tal modo, adverte-se para a necessidade de valorização das questões socioambientais no processo de planejamento, pois os espaços livres públicos, de modo geral, e as áreas verdes, de modo particular, são fundamentais para um legítimo desenvolvimento urbano.

\section{OBJETIVOS}

O objetivo geral deste trabalho é analisar a relação existente entre espaços livres públicos, nomeadamente os espaços verdes urbanos, e as condições de saúde e qualidade de vida da população, considerando diferentes perspectivas do planejamento urbano. De modo específico, o artigo visa contribuir para com a discussão acerca da necessidade de mudanças positivas nos espaços livres de uso público nas cidades, com destaque para as brasileiras, a partir do processo de planejamento urbano que preze pela participação popular.

\section{METODOLOGIA}

Para o alcance dos objetivos propostos, a metodologia utilizada consistiu basicamente em uma revisão da literatura. Foram realizadas leituras de livros e de trabalhos acadêmicos (teses, dissertações, artigos) e trabalhos técnicos (documentos e estudos oficiais elaborados por órgãos, institutos e centros de pesquisa) disponíveis em bases de dados internacionais e nacionais. A redação deste artigo justifica-se pela contribuição para com as discussões sobre a relevância de se (re)valorizar os espaços livres públicos, nomeadamente dos espaços verdes urbanos, considerando a necessidade de que tal tendência seja considerada nas políticas públicas, que devem assegurar as condições para o alcance da saúde e da qualidade de vida nas cidades.

\section{RESULTADOS:}

\section{Influências dos Espaços Verdes Urbanos na Saúde}

O estabelecimento da relação entre a saúde e o ambiente não constitui uma novidade, ainda que ao longo da História a relevância do ambiente no processo saúde-doença tenha apresentado diferentes leituras. O primeiro momento em que a importância do ambiente na saúde foi enfatizada ocorreu quando Hipócrates (460-377 a.C.), escreveu a obra "Ares, águas e lugares", destacando o papel do ambiente na gênese, determinação e evolução das doenças. Posteriormente, entre os séculos XVII e XIX, a Teoria dos Miasmas igualmente concebeu a transmissão das doenças, pela ventilação/aeração e, com as transformações sociais no século XIX, pelas condições de vida e trabalho das populações na sociedade em vias de industrialização (GOUVEIA, 1999).

No planejamento urbano, até mesmo no âmbito de vertentes que repudiavam o racionalismo e 
se pautavam na arte, como Camillo Sitte, os aspectos higiênicos estavam entre os objetivos prioritários. De acordo com o autor, o verde na paisagem, constitui-se por dois elementos; a água e a vegetação, que podem ser utilizados de forma sanitária ou decorativa. O primeiro tem como função a saúde, através da circulação do ar e respiração enquanto o segundo tem como função unir os edifícios e praças para tornar o ambiente mais belo (SITTE, 1992).

No contexto da industrialização, segundo Madureira (2012), sobretudo por razões de saúde pública e, em segundo plano, por motivos recreativos e educativos dos habitantes das cidades são concebidos por higienistas espaços livres, jardins e parques públicos, bem como ganham força os movimentos coletivos para a criação destes espaços. As transformações na intencionalidade da criação dos espaços livres continuaram, passando principalmente à recreação e, posteriormente à conservação da natureza, segundo Douglas,1983, apud Nucci (2008, p.28):

\begin{abstract}
[...] Open spaces ou green spaces nas cidades [...] entre 1930 e 1970 as áreas vegetadas foram designadas essencialmente para esporte e recreação ou jardins formais. O planejamento da vida silvestre na cidade cresceu com os grandes esforços em conservar a vida silvestre em seus habitats naturais [...] A diversidade biológica nas áreas urbanas pode ser alcançada por meio de ações prescritas por leis, ou constrangimento legal, ou pelo desenho urbano [...].
\end{abstract}

Na segunda metade do século XIX, com os estudos de Louis Pasteur (1822-1895) e Robert Koch (1843-1910), relegou-se para segundo plano a importância do ambiente físico e social no processo saúde-doença, que passou a ser compreendido a partir da perspectiva microbiana ou bacteriológica. Essa visão também valoriza espaços oxigenados e abertos, mas o ambiente passou a ser compreendido enquanto o local de interação entre os agentes da doença e o hospedeiro humano suscetível (GOUVEIA, 1999). Neste contexto, até meados do século XX, à medida que as condições ambientais melhoravam e as intervenções médicas se tornavam mais eficazes, reduziam-se as preocupações do movimento de saúde pública 'sanitarista' (HUNT et al., 2000 apud MORRIS, 2003). Entretanto, as intensas transformações socioambientais, que implicaram em certa medida a redução da qualidade ambiental e da saúde das pessoas, fizeram com que recentemente, entre a segunda metade do século XX e início do XXI, essas duas áreas voltassem a se convergir.

A relação benéfica dos EVU e a saúde pública faz parte do senso comum. Contudo, a difusão da literatura científica dos estudos epidemiológicos sobre essa relação, na perspectiva do bemestar e da saúde física e mental, ainda são restritos e relativamente recentes (MAAS et al., 2006; SANTANA et al. 2010). No Brasil essa abordagem, que de modo quantitativo e qualitativo indicam a relação entre saúde e acesso aos EVU, ainda é imperceptível e foca-se puramente nos índices de áreas verdes (IAV), sobre os quais ainda não existe uma formulação consistente, pois, conforme observa Nucci (2008) para o contexto de São Paulo, cada fonte apresenta 
índices diferentes para o mesmo período e, o que é mais grave, a mesma fonte pode apresentar índices diferentes para o mesmo período de estudo.

Em outros contextos, como o europeu, já são vários estudos que indicam benefícios diretos e indiretos dos EVU relacionando-o com do estado de saúde autoavaliado e longevidade (MACINTYRE et al., 1993; DIEZ-ROUX et al., 1999; DUNN; HAYES, 2000; ROSS, 2000; TAKANO et al., 2002; DE VRIES et al., 2003; HARTIG e EVANS, 2003; MORRIS, 2003; CHIESURA 2004, MAAS et al. 2006; NOGUEIRA, 2006; SANTANA et al., 2007; 2010); com a melhoria da qualidade ambiental (WHITFORD et al., 2001; ALCOFORADO e ANDRADE, 2007; VASCONCELOS e VIEIRA, 2007); na potencialização da capacidade de concentração e disciplina das crianças nas atividades cotidianas (TAYLOR et al., 2001); no estímulo à imaginação e criatividade, a sensação de liberdade, aspectos cognitivos e à saúde mental de crianças (MALLER et al. 2009); no alívio do stress urbano (ULRICH, 1984; LORENZI, 1992; GRAHN e STIGSDOTTER, 2003; MALLER et al., 2006; NIELSEN e HANSEN, 2007; TZOULAS et al. 2007; ABKAR et al. 2010) e da fadiga, com consequências na diminuição da agressividade e da violência (KUO et al. 1998; KUO e SULLIVAN, 2001; DOYLE et al., 2006), e influenciam até a capacidade de relacionamento com os vizinhos e os sentimentos de pertença a um lugar (bairro, cidade) (KIM e KAPLAN, 2004).

Os estudos não se restringem apenas aos citados, assim como apresentam modelos de análise e formas de abordagem diversificadas, mas de modo geral, apresentam uma concordância expressiva entre os pesquisadores sobre a associação positiva entre os espaços verdes, especialmente considerando seu acesso e as condições de saúde da população. Neste sentido, em uma estratégia de desenvolvimento de uma cidade saudável é necessário que as questões ambientais sejam reincorporadas nas políticas de saúde pública, considerando os diferentes setores do planejamento urbano. A notoriedade social desta demanda é crescente, por vezes, passa de um direito a exigência dos cidadãos. Conforme destacam Gómez, Costa, Santana (2014, p.50) a população preza cada vez mais o bem-estar, a saúde (física e mental) e a ocupação dos tempos livres, a oferta de um espaço verde próximo da residência e do local de trabalho - proporcionando convívio, contato com a natureza, prática de atividade física, entre outras.

Considerando que os investimentos públicos em espaços verdes saudáveis podem reduzir as despesas com cuidados de saúde, Tzoulas et al. (2007) destacam a necessidade de articular a ligação entre infraestrutura verde, ecossistema e saúde humana e o bem-estar, de forma que esta relação seja compreendida por aqueles que trabalham em diferentes disciplinas (urbanistas, políticos, ecologistas, cientistas sociais etc.) oferecendo oportunidade para a colaboração interdisciplinar no planejamento urbano, como foi recomendado em um número de estudos (BERKES e FOLKE, 1998; HAEUBER e RINGOLD, 1998; COLLINS et al., 2000;. DEVUYST et al., 2001 ; KINZIG e GROVE, 2001; EHRLICH, 2002 apud TZOULAS et al., 2007). Neste sentido, a partir da definição de saúde humana como um estado ideal de bem-estar 
concepções espaciais e estéticas, deve ser considerada pelos profissionais incumbidos pela (re)construção das cidades, de modo a criar ambientes mais agradáveis e sadios, propiciando a geração de saúde e bem-estar à população no contexto de uma sociedade essencialmente urbana.

\section{Elementos Essenciais para um Ambiente Urbano Saudável na Perspectiva dos Espaços Públicos Verdes Urbanos}

As críticas de Jacobs (2000) à cidade moderna e à realidade urbana dela decorrente, apesar de terem sido formuladas há meio século, ainda parecem ser válidas para as cidades atuais. Afinal, permanece a dificuldade em projetá-las como funcionais e saudáveis, tendo em conta as condições para a vitalidade urbana, o comportamento social e a morfologia urbana.

Nas cidades hodiernas verifica-se o empobrecimento da vida urbana em decorrência das edificações se virarem de costas para o espaço público, renegando-o, esvaziando-as da vida pública e interiorizando as práticas sociais, pela ilusão do isolamento e da privacidade. Por outro lado, o aumento do sentimento de insegurança nos espaços públicos se opõe ao sentimento de proteção, higiene, respeito, organização dos espaços privados abertos ao público como os centros comerciais e os parques temáticos. Para além disso, pode ocorrer uma diminuição dos deslocamentos físicos em decorrência de um correlativo aumento das comunicações à distância e, sobretudo do fluxo veicular, afinal é cientificamente comprovado que nos locais com trânsito intenso a possibilidade de interação entre as pessoas é menor (GONÇALVES, 2004).

Torna-se necessário a retomada e adaptação à cidade contemporânea de valores da cidade antiga, como a dimensão coletiva e comunitária da cidade, em que o espaço público apresente grande valor social. Assim ganham destaque, aspectos como a perspectiva do cidadão, a cidade plurifuncional, entre outros apregoados pelo "Novo" Urbanismo, que poderia designarse por um velho novo urbanismo. Considerando os espaços públicos além de ofertá-los, de acordo Gonçalves (2004, p. 64), é necessário torná-los mais sedutores à permanência do que outros espaços alternativos, especialmente os espaços privados como shopping centers ou parques temáticos.

Conforme alerta Jane Jacobs, ([1961] 2000) no modernismo difundido por Le Corbusier e Ebenezer Howard, o modelo das Cidades-Jardins, caracterizadas pelo tecido urbano esparso com edifícios isolados, zoneado, com a segregação de usos e separação entre a circulação de pedestres e veículos e entremeado fisicamente por grandes parques públicos, produz deterioração ambiental, econômica e social. Afinal, a suburbanização causa impactos decorrentes da dependência do automóvel, como o aumento da poluição, devastação de florestas e terras agrícolas e aumento dos custos da urbanização, bem como enfraquece o espírito comunitário. Sendo que o isolamento entre os espaços livres impossibilita a 
consumação de redes de corredores verdes (greenways), que integram a infraestrutura verde, trazendo além dos prejuízos sociais, destacados por Jacobs, prejuízos à biodiversidade.

Os impactos decorrentes da regularização urbana, como o afastamento das pessoas já haviam sido destacados por Camillo Sitte em 1889 sua obra "A construção das cidades segundo seus princípios artísticos", a qual ainda continua sendo atual. Embasado na teoria Aristotélica de que "uma cidade deve ser construída para tornar o homem ao mesmo tempo seguro e feliz" (SITTE, [1889]1992, p. 14) o autor defende que, para tal é necessário considerar a visão do cidadão em seus variados percursos pela cidade. Com relação aos EVU de acordo com Sitte, eles devem ter um tamanho pequeno e estar espalhados por entre os edifícios da cidade.

Tal como as cidades os espaços públicos, incluídos os espaços verdes urbanos (EVU), se metamorfoseiam ao longo dos anos, assumindo diferentes formas e funções de acordo com as concepções urbanísticas e valores da sociedade em cada época. Considerando as transformações dos espaços verdes, segundo Madureira (2012) na base da política de criação de jardins e parques públicos inicialmente, estiveram, sobretudo argumentos de base higienista e social, enquanto atualmente os benefícios e funções atribuídos às áreas verdes são mais vastos e têm vindo a constituir uma premissa essencial das políticas e programas de desenvolvimento sustentável em variadas áreas setoriais. Na mesma perspectiva, de que os EVU, nomeadamente os parques, atualmente são multifuncionais servindo à realização de diversas atividades de lazer. Azevedo (2013) ressalta que atualmente há o retorno dos projetos de espaços livres para requalificar as cidades. Os jardins voltam às cidades, mas com características próximas à arte, à agricultura e à ecologia, diferente do século XIX, quando caracterizavam pelo estilo paisagístico. Nas palavras do autor:

\begin{abstract}
[...] após um período de racionalização da sociedade urbana, levanta-se uma vontade de realização de projetos com o objetivo de humanizar o espaço urbano, devolver a cultura do encontro à cidade e introduzir outra "velocidade" na vivência urbana; construir espaços para o lazer e passar do automóvel para o pedonal. Desde projetos de conversão de grandes infraestruturas, a menores projetos de aproveitamento de espaços vazios da cidade, cresce uma vontade generalizada de reforçar o vínculo entre os habitantes, o espaço das cidades e natureza. Para além dos temas enunciados por Batlle - arte, agricultura e ecologia - jardins e parques irão abraçar também o processo de transformação que opera nas cidades contemporâneas, não menos pertinente, participando do seu desenho. (AZEVEDO, 2013, p.79).
\end{abstract}

De acordo com Gonçalves (2004) nas atuais intervenções urbanas, os espaços públicos são concebidos de acordo com as circunstâncias do tempo e modo associado ao lugar, na perspectiva de "fora para dentro", isto é, do exterior (espaço públicos) para o interior (fachada, edifício). 
Com foco nas funcionalidades da vegetação no meio urbano, de acordo com autores como Lamas (2004) o que caracterizam a imagem da cidade, são elementos de composição e do desenho urbanas sendo várias evidências de maiores benefícios da arborização das ruas, o que não exclui a necessidade da existência de praças e parques, os quais seriam conectados pelos corredores verdes, tal como fez o barão de Haussmann, entre 1853 e 1869, em Paris, na França e, Cerdá e Castro em 1860 com as intervenções em Barcelona e Madrid na Espanha, provendo estas cidades de espaços verdes espalhados de forma homogênea por toda a cidade, interconectados por ruas arborizadas. Neste sentido, destaca-se os "boulevards" parisiense e as Ramblas Catalãs, zonas pedonais que favorecem as experiências sociais e culturais. Conforme alerta Lamas (2004, p.418):

[...] a simples árvore plantada em caldeira, alinhada ao longo de passeios pavimentados, releva-se mais útil benéfica sob o ponto de vista ambiental e climático do que maciços de plantas, canteirinhos e outros elementos vegetais. Umas filas de arvores bem posicionadas qualificam muito mais o espaço urbano do muitos pequenos espaços verdes residuais e dispersos no meio de prédios dispersos. (LAMAS, 2004, p.418).

Madureira (2012, p.39) ao tratar da "infraestrutura verde", "entendida como um sistema integrado de áreas verdes multifuncionais que relaciona a cidade com a sua envolvente, enquanto infraestrutura biofísica e social integrante do território" no contexto da cidade contemporânea, destaca que há, paradoxalmente, uma grande ameaça advinda do alastramento disperso da urbanização, com a consequente diminuição e fragmentação das áreas verdes, que acabou por dar maior visibilidade ao desafio, à oportunidade e à necessidade daquela. Em síntese, a autora destaca que:

[...] o grande desafio para o desenho da infra-estrutura verde nesta cidade alargada será conseguir incorporar os seus valores ambientais e sociais num território diverso daquele que conhecíamos no passado. Respondendo simultaneamente ao desafio da continuidade/conectividade e à oportunidade da multifuncionalidade, potencia-se 0 seu carácter infraestruturador do território. (MADUREIRA, 2012, p.40).

Além disso, como observou Jacobs (2000) os espaços públicos, incluindo os EVU, precisam de controle social, ao qual também se relaciona a vitalidade destes e de seu entorno, resultante da maneira de como a vizinhança neles interfere. Se no princípio do século XIX, as características espaciais da cidade e a escala humana dos deslocamentos valorizavam tais espaços, haja vista que como destaca Gonçalves $(2004$, p.98) "tanto na escala horizontal como na vertical existia uma contenção real, havendo condições para uma grande intensidade de interacções sociais", com o advento dos transportes, de acordo com o autor, "o espaço 
intermédio deixou de constituir uma experiência para quem se desloca apresentando-se desfocado e sem condições para o contato pessoal" inaugurando uma crise do espaço público urbano, expressa, sobretudo a partir da dimensão física dos mesmos.

Reduzem-se os largos e as praças, bem como os espaços verdes utilizáveis junto às áreas residenciais ao passo que ganham ênfase situações como os parques verdes situados no centro de condomínios, os quais se mostram insuficientes para a proporção espaço verde/habitante. Por outro lado, os grandes EVU revelam problemas de localização, muitas vezes apenas acessíveis por automóvel, e revelando sentimentos de insegurança pelo excesso de vegetação, deficiência de iluminação e vigilância limitada (GONÇALVES, 2004). É também sabido que os grandes EVU têm manutenção mais cara, maior risco de degradação sendo também responsáveis pelo aumento da criminalidade. Tal como destacado por Sitte (1992) e Jacobs (2000), o sentimento de segurança nos espaços públicos influencia a utilização e vivência destes espaços.

Com relação, ao desenho urbano Jacobs (2000) ressalta que a compreensão da "ordem inata e funcional" deve preceder a definição de princípios que o orientem. Para a implantação dos espaços verdes destaca-se a importância de que sejam considerados os "fatores sociais (características, necessidades e opinião da população) e os objetivos ou funções de cada área em relação a estes aspectos" conhecidos por meio de inquéritos aos usuários (HILDEBRAND et al., 2001).

Além da demanda social há igualmente fatores que influenciam a utilização e a frequência desses espaços, dentre os quais Gómez, Costa, Santana (2014, p.50) destacam as características dos espaços verdes: localização, dimensão, segurança, limpeza, manutenção, sinalização, equipamentos, adequação à prática de atividades esportivas, etc. Com efeito, para assegurar os efeitos positivos dos EVU sobre a saúde da cidade e a saúde na cidade, as intervenções devem considerar não só os aspectos infraestruturais, mas também os espaços envolventes e/ou quem os utiliza, tendo em atenção a sua manutenção, uma vez que a percepção de espaço verde abandonado ou vandalizado pode ter efeitos negativos no bemestar das populações, aumentando a ansiedade causada pelo medo do crime (KUO et al., 1998 apud SANTANA et al. 2007).

Para a condição de vitalidade dos espaços públicos, a partir da interação social, seja assegurada Jacobs (2000. p.105) destaca 4 critérios:

1. Complexidade; refere-se à variedade de usos e, por conseguinte de usuários dos parques. Essa variedade implica diversidade de horários e de motivos para sua utilização. Como explica o autor "Eles utilizam o parque em horários diferentes porque seus compromissos diários são diferentes. Portanto, o parque tem uma sucessão complexa de usos e usuários". A complexidade, portanto diz respeito muito mais às 
diferenças visuais do que ao desenho do espaço, de modo que quando em uso os espaços apresentam-se mais complexos do que quando estão vazios;

2. Centralidade diz respeito ao elemento de grande importância, trata-se do lugar reconhecido como o centro. Ele possui hierarquia superior aos demais e atua como referência no espaço da praça, atuando como polarizador dos usos e da legibilidade do espaço. Segundo o autor estes centros dos parques e praças "servem de palco às pessoas";

3. Insolação traduzida pela combinação de boas áreas de sombra para o verão e de áreas ensolaradas para os dias de inverno.

4. Delimitação espacial, seguindo a linha que Sitte defendia no final do século XIX, de que os espaços públicos deveriam ser abertos, no que se refere ao acesso público e ao fato de não possuírem cobertura, mas "fechados" no que se refere ao seu aspecto perspectivo, tendo em vista que eram constituídos por complexos arquitetônicos "fechados" visualmente por espaços edificados. Não devem, tampouco, formar imensas áreas vazias sobre as quais os edifícios se assentam como defendia o Modernismo. A boa localização dos parques combinada com a prestação de serviço adequada é responsável pela atração de frequentadores.

Em relação a este último aspecto conforme destaca Azevedo $(2013$, p.56) ao conceber o Central Parque Fredrick Law Olmsted em parceria com Calvert Vaux buscaram o contraste com a paisagem de Nova lorque, sendo claros os limites do parque e a demarcação de uma fronteira não só espacial, mas também funcional. A clareira do parque inglês no interior do Central Park, com "bosques" densos nos seus limites, cria uma sensação de resguardo em relação à cidade, permitindo a vivência do campo dentro da cidade.

Essa mesma opinião de que a vitalidade dos espaços públicos decorre da receptividade dos mesmos às pessoas para circulação e permanência, tem sido defendida por autores contemporâneos como o arquiteto dinamarquês Jan Gehl, com o pressuposto da criação de cidades para as pessoas. As pessoas são o ponto de partida para tratar de temas como habitação, revitalização dos centros das cidades, segurança, espaços públicos de convivência etc.

Na obra "New City Life" (GEHL et al., 2006) são apresentados aspectos para se construir cidades vivas, seguras, sustentáveis e saudáveis, que sejam lugar de encontro, boa para caminhar e para pedalar, a partir do resgate do espaço público como um lugar agradável ao convívio de pedestres e de ciclistas, sem o domínio do carro.

Com inspiração em conceitos de autores clássicos como Jane Jacobs e/ou contemporâneos como Jan Gehl, observa-se um movimento de retomada pelo interesse em reforçar a importância dos espaços públicos no âmbito das cidades contemporâneas, especialmente considerando o placemaking, entendido como o processo de planejamento, criação e gestão 

Figura 3- Desafios e mecanismos de ação e implementação para a melhoria dos espaços públicos.

\begin{tabular}{|c|c|}
\hline & \\
\hline Desafios & \\
\hline $\begin{array}{l}\text { Abordagem de planejamento centrado } \\
\text { nas pessoas. }\end{array}$ & \\
\hline $\begin{array}{l}\text { Espaço público inclusivo para todos } \\
\text { grupos, particularmente para os mais } \\
\text { vulneráveis. }\end{array}$ & $\begin{array}{l}\text { Mecanismos de ação e de } \\
\text { implementação }\end{array}$ \\
\hline O espaço público que respeite escala e & Advocacy e Mobilização \\
\hline comportamento humano. & Medição e Monitoramento \\
\hline $\begin{array}{l}\text { A rede municipal de ruas e espaços } \\
\text { públicos. }\end{array}$ & $\begin{array}{l}\text { Soluções Espaço Público de } \\
\text { Financiamento }\end{array}$ \\
\hline Produtividade econômica do espaço & Políticas e legislação Espaço Público \\
\hline público. & Empoderamento de grupos \\
\hline Acesso ao espaço público - esferas & marginalizados \\
\hline pública e privada. & Ferramentas e Gestão do \\
\hline $\begin{array}{l}\text { Espaços públicos sustentáveis, } \\
\text { saudáveis, seguros, resilientes, com } \\
\text { poupança energética e utilização } \\
\text { eficiente dos recursos. }\end{array}$ & Conhecimento \\
\hline Cultura e contexto do espaço público. & \\
\hline
\end{tabular}

Fonte: Adaptado de future of places (2015). Org: Alves, 2016.

Pela abrangência da Habitat III, a inciativa de se buscar colocar o espaço público na "Nova Agenda Urbana" para o século 21, apresenta-se com grande relevância para a mudança da abordagem destes espaços, para encorajar a tomada de medidas imprescindíveis a um processo de construção de cidades mais sustentáveis e saudáveis, como a participação social, a interação criativa, a igualdade de oportunidades etc. melhorando assim a qualidade de vida de todos.

\section{CONSIDERAÇÕES FINAIS}

Buscou-se ressaltar, neste trabalho, a relação existente entre espaços livres públicos, especificamente os espaços verdes urbanos, e as condições de saúde e qualidade de vida da população, utilizando-se do resgate histórico do entendimento da determinação do processo saúde-doença pelo ambiente, bem como diferentes visões dos espaços livres no âmbito do processo de planejamento urbano.

Ao considerar as características do momento atual, em que os processos de urbanização e globalização se difundiram em nossa sociedade, fica evidenciado o aumento da demanda por espaços livres para assegurar os benefícios sociais e ambientais, a partir do contato com a natureza, do desfrute de momentos de lazer e recreação. De tal modo, atualmente em muitas 
realidades pode-se verificar iniciativas, tanto no âmbito do planejamento como por iniciativas populares, com o fito de buscar por saúde e qualidade de vida tendo como base a concepção e utilização dos espaços públicos. Porém, é preciso ter em conta que a compreensão da relevância dos espaços livres públicos passou por momentos de (des)(re)valorização, apresentando também particularidades de acordo com as características socioculturais, afinal a construção de cidades reflete as necessidades e individualidades das sociedades/pessoas.

Deste modo, tendo em conta as experiências concretas e as contribuições de estudiosos como Jane Jacobs, Clare Cooper Marcus, William H. Whyte, Jan Gehl, entre outros, fica claro que é fundamental um processo de planejamento, que valorize as questões socioambientais. Ainda considerando os referidos estudiosos ressalta-se a importância de uma abordagem bottom-up, a participação dos cidadãos, na concepção e funcionamento dos espaços públicos, que se propagam pela comunidade, transformando e melhorando a vida na/da cidade e as interações entre as pessoas e destas com o lugar ou mesmo walkability (Jeff Speck Farrar), da qual depende a riqueza, saúde, habitabilidade e a vitalidade das cidades. Outro ponto de grande valor é a interligação entre os diversos espaços públicos no âmbito da cidade com boa acessibilidade.

\section{REFERÊNCIAS}

ARENDT, H. A Condição Humana. Rio de Janeiro: Editora Forense, 2005.

AZEVEDO, I. T. T. Os Jardins da Cidade: do jardim privado aos espaços verdes enquanto elementos estruturantes do espaço urbano. 163f. 2013. Dissertação (Mestrado em arquitetura) - Faculdade de Ciências e Tecnologia da Universidade de Coimbra. Coimbra, 2013.

CAVALHEIRO, F.; DEL PICCHIA, P. C. D. Áreas verdes: conceitos, objetivos e diretrizes para o planejamento. In. 10 Congresso Brasileiro Sobre Arborização Urbana e $4^{\circ}$ Encontro Nacional Sobre Arborização Urbana.1992, Vitória - ES. 10 Congresso Brasileiro Sobre Arborização Urbana e $4^{\circ}$ Encontro Nacional Sobre Arborização Urbana. 1992. p. 2938.

CAVALHEIRO, F. et al. Proposição de terminologia para o verde urbano. Boletim Informativo Sociedade Brasileira de Arborização Urbana, Rio de Janeiro: SBAU, ano VII, n.3, p.7, jul./ago./set. 1999.

GEHL, J., et al. New city life.Published by ArkitektensForlag - The Danish Architectural Press, 2006.

GÓMEZ, A.; COSTA, C.; SANTANA, P. Acessibilidade e utilização dos espaços verdes urbanos nas cidades de Coimbra (Portugal) e Salamanca (Espanha).Finisterra, v. XLIX, n.97, p. 49-68, 2014.

GONÇALVES, J. M. Os Espaços Públicos na Reconfiguração Física e Social da Cidade. 398f. 2004. Tese (Doutorado em Geografia) - Universidade de Nova de Lisboa, Lisboa, 2004.

GOUVEIA, N. Saúde e Meio Ambiente nas Cidades: Os Desafios da Saúde Ambiental. Saúde e Sociedade. v. 8, n. 1, p. 49-61, 1999. 
